\title{
Entrevista: Yves Clot
}

Nesta edição apresentamos uma entrevista com o professor Yves Clot, psicólogo do trabalho e pesquisador do CNAM, Conservatoire National des Arts et Métiers de Paris. Ele é autor do livro A função psicológica do trabalho, publicado pela editora Vozes em 2006. Fez o prefácio de um dos livros de Louis Le Guillant, intitulado Escritos de Le Guillant - da ergoterapia à psicopatologia do trabalho, organizado por Maria Elizabeth Antunes Lima e também publicado pela editora Vozes, em 2006. A entrevista foi realizada em Florianópolis, durante o XI Simpósio da Associação Nacional de Pesquisa e Pós-Graduação em Psicologia (ANPEPP), no dia 18 de maio de 2006, ocasião em que Yves Clot proferiu palestra sobre o método de pesquisa em psicologia do trabalho e participou de reuniões com pesquisadores de alguns dos Grupos de Trabalho. A entrevista é uma realização do Grupo de Trabalho da ANPEPP denominado "Trabalho e Processos Organizativos na Contemporaneidade". Participaram da entrevista os professores Dulce Helena Penna Soares, Maria Chalfin Coutinho (ambas da UFSC), Henrique Caetano Nardi ${ }^{1}$ (UFRGS) e Leny Sato (USP). Contamos também com a generosa contribuição da professora Maria Elizabeth Antunes Lima (UFMG) - profunda conhecedora da obra de Yves Clot e uma de suas divulgadoras no Brasil para o trabalho final de edição técnica do texto abaixo. Nesta entrevista mostra-se a importância da reflexão fomentada pelo movimento da saúde do trabalhador para o desenvolvimento do campo da psicologia do trabalho.

Leny Sato - Antes de iniciar a entrevista, gostaria de agradecer ao professor Yves Clot por, gentilmente, nos conceder esta entrevista. Eu pediria ao professor, inicialmente, que nos falasse sobre sua formação.

Yves Clot - Eu fiz filosofia. Fiz uma tese de filosofia com Yves Schwartz, em Aix-enProvence, que se chama $O$ trabalho: entre a atividade e a subjetividade. Essa tese aborda a análise do trabalho e, por essa via, uma análise da psicologia do trabalho. Assim, a psicologia do trabalho foi o objeto de minha tese de filosofia. Foi a história da ciência sobre a psicologia do trabalho e, de um outro ponto de vista, interessei-me pela prática no trabalho, a transformação do trabalho. Foi uma maneira de pensar muito inspirada no trabalho de Ivar Oddone $^{2}$. Do ponto de vista de minha formação foi, inicialmente, uma tese de filosofia e, em seguida, uma habilitação em psicologia. Quando eu entrei no CNAM, diziam-me que haveria a necessidade de eu atuar na intervenção em situações profissionais e, portanto, deveria fazer da psicologia meu métier. Não simplesmente dedicar-me à reflexão sobre a psicologia (uma filosofia da psicologia), mas preocupar-me com a prática, o que está ligado ao fato de antes disso ter trabalhado com orientação profissional em colégios, o que foi uma atividade prática. Refleti sobre essa prática, na tese, com instrumentos da filosofia e depois eu reencontrei Ivar Oddone, que eu conheci bem, na Itália. Eu trabalhei com Ivar Oddone, não regularmente, e nos anos 1980 eu decidi traduzir um de seus livros que foi publicado em 1977, em italiano, sob o título, Esperienza operaia, coscienza di classe e psicologia del lavoro ${ }^{3}$; em francês, o título recebido foi Redécouvrir l'expérience ouvrière - vers un autre psychologie du travail ${ }^{4}$. Eu fiz também a apresentação desse livro. Eu decidi traduzi-lo porque ali está posto que o problema

1 Henrique Nardi não participa desse Grupo de Trabalho, mas partilha a liderança, com Leny Sato, de Grupo do Pesquisa registrado no CNPq, intitulado "Trabalho e Processos Organizativos na Contemporaneidade".

2 Ivar Oddone, psicólogo italiano, atuou como assessor de conselhos de trabalhadores, entre nós, ficou conhecido como um dos propositores do Mapa de Risco e do Modelo Operário Italiano. No Brasil, a partir da década de 80, teve influência importante no trabalho desenvolvido na área de Saúde do Trabalhador, tanto nos órgãos sindicais, como nos serviços públicos de saúde. Ficou conhecido como um dos autores do livro Ambiente de trabalho: a luta dos trabalhadores pela saúde, juntamente com Gastone Marri, Sandra Gloria, Gianni Briante, Mariolina Chiattella e Alessandra Re, editado em 1986 pela Hucitec de São Paulo.

3 Os autores são Ivar Oddone, Alessandra Re e Gianni Briante.

4 Editado em Paris, 1981, pela Messidor/Editions Sociales. 
não seria o de propor uma psicologia do trabalho alternativa, mas de mudar os protagonistas da psicologia do trabalho. Essa é uma idéia muito forte de Oddone, que é a de os trabalhadores "entrarem" na psicologia do trabalho por meio da "comunidade científica ampliada" e, de certa maneira, seria a psicologia do trabalhador. Assim, deve-se mudar a maneir a de fazer a psicologia do trabalho e não propor uma outra psicologia do trabalho. E essa idéia eu desenvolvo na minha tese de doutorado com a orientação de Yves Schwartz. É uma idéia dele: a necessidade de transformar a comunidade científica. A comunidade científica deveria deixar ao trabalhador a possibilidade de ele mesmo afetar e controlar a psicologia do trabalho mediante formas de cooperação entre eles, como a co-análise do trabalho, que é o dispositivo de transformação. O ponto de partida da minha entrada na disciplina da psicologia do trabalho seria, então, propor uma nova forma de atividade comum no mundo do trabalho, com os trabalhadores.

Leny - Oddone diz que há uma psicologia do trabalho não escrita.

Clot - Sim, uma psicologia do trabalho não escrita, informal, que pode ser a fonte para o desenvolvimento da psicologia do trabalho escrita. Foi isso que me interessou. E há vinte e cinco anos eu pesquiso o meio, o trabalho das pessoas, porque Oddone tem um espírito prático e tem o interesse, a preocupação, de saber "como", não "o que" os trabalhadores sabem, mas "como". Eu penso que aprendi com ele a ter essa preocupação. Por isso eu considerei que a perspectiva filosófica me ajudaria: eu me perguntava "como" os trabalhadores sabem e o dispositivo metodológico, o que eu denominei "clínica da atividade", que seria o meio de mudar a psicologia do trabalho junto com os trabalhadores, e vice-versa, pois esse dispositivo permite que os trabalhadores, com a psicologia do trabalho, desenvolvam sua capacidade de agir.

Leny - Em algum lugar eu li, não me lembro onde, que Ivar Oddone sofreu uma influência do Paulo Freire, você sabe se essa influência existe?

Clot - Não conheço a presença dessa influência, mas conheço um pouco o trabalho do Paulo Freire e há convergências evidentes. Mas o trabalho de Oddone está vinculado ao movimento dos conselhos de trabalhadores nos locais de trabalho, em Turim (Itália) na década de 70. A perspectiva de Oddone é influenciada por esse movimento dos conselhos nos locais de trabalho e ele considera importante a participação dos trabalhadores na psicologia do trabalho. Ele também se preocupa com o enfraquecimento do movimento dos trabalhadores. Mas hoje é muito difícil manter exatamente o mesmo caminho que foi adotado àquela época, pois a conjuntura histórica é muito diferente. Nós nos colocamos a questão de saber como institucionalizar essa psicologia do trabalho, a de uma "comunidade científica ampliada", como proposta por Yves Schwartz: de construir o conhecimento na universidade junto ao sindicalismo, de possibilitar a formação continuada e que o sindicalismo sirva-se da universidade para seu crescimento. E eu estive muito ligado a essa experiência, em Aix-enProvence, com Yves Schwartz, e no CNAM eu continuo com essa perspectiva. A história do CNAM é também a da promoção social, de acolher trabalhadores de diversas atividades para promover o seu desenvolvimento. Como dizia, eu continuo com essa perspectiva que abre a possibilidade de acolher trabalhadores de todas as profissões, para virem e desenvolverem a experiência profissional. Eu tentei estruturar no CNAM, na formação em psicologia do trabalho, algo que se beneficiasse da experiência de Oddone numa conjuntura histórica muito diferente daquela em que ele a elaborou, de transformar a psicologia do trabalho, nessa perspectiva, em disciplina acadêmica. Esse é meu projeto.

Henrique Caetano Nardi - Na conjuntura política atual, como fica essa psicologia do trabalho? Aqui no Brasil, a psicologia do trabalho ligada à gestão de recursos humanos "à americana" é forte. Como isso se passa na França?

Clot - Na França, a psicologia do trabalho jamais se voltou completamente para a psicologia industrial "à americana". Certamente há a psicologia industrial clássica na França, mas é

\section{0}


menos forte que em outros países da Europa; não é, por exemplo, como na Espanha e na Alemanha. A originalidade francesa é muito forte. Na França há duas razões para a psicologia do trabalho não se transformar na psicologia industrial: a presença da tradição da ergonomia, muito forte, a ergonomia francófona, ergonomia da atividade, com o trabalho de Alan Wisner ${ }^{5}$, que contribuiu muito. Nessa perspectiva, a ergonomia propõe a distinção entre trabalho prescrito e trabalho real, entre tarefa e atividade. Ela utiliza-se do pensamento da psicologia soviética de Leontiev. A ergonomia francófona opõe-se à psicologia industrial, à psicotécnica e à psicologia dos recursos humanos. É uma oposição forte, bastante desenvolvida na França, sobretudo no CNAM. A psicologia do trabalho analisa o trabalho no sentido dado pela ergonomia. A segunda razão é que na França há o desenvolvimento da psicopatologia do trabalho, também muito original, com os trabalhos de Le Guillant e outros. Há uma psicopatologia do trabalho bem particular. Há, então, duas raízes muito fortes: psicopatologia do trabalho e ergonomia. Elas protegeram, poderíamos assim dizer, a disciplina psicologia do trabalho da psicologia industrial. Quando eu entrei no CNAM, havia algumas influências: de Oddone, da psicopatologia do trabalho e da ergonomia. Christophe Dejours também desenvolvia seus estudos em psicopatologia do trabalho.

Dulce Helena Penna Soares - E quando você entrou no CNAM?

Clot - Em 1990, há quinze anos. Quando eu cheguei ao CNAM, comecei a trabalhar com Christophe Dejours e, depois, há cerca de um ano, temos duas cadeiras. Uma de Christophe Dejours, que tem uma cadeira de psicanálise, saúde e trabalho e uma de psicologia do trabalho, da qual eu sou o titular. Há três abordagens: a psicopatologia do trabalho, a ergonomia e, poderia dizer, a contribuição de Oddone. E, para conseguir trabalhar todas essas abordagens conjuntamente, eu fiz uma releitura, uma re-análise do trabalho de Vigotski, que, no fundo, é uma psicologia que me permite integrar essa tradição da psicologia. Nessa cadeira de psicologia do trabalho, no CNAM - evidentemente não é a psicologia do trabalho como um todo, mas uma parte da psicologia do trabalho na França -, nós desenvolvemos o que denominamos de "clínica do trabalho". Não digo que é "psicologia clínica do trabalho", mas sim uma "clínica do trabalho", que visa a ação sobre o campo profissional e busca desenvolver a capacidade de agir dos trabalhadores sobre eles mesmos e sobre o campo profissional. Então, poderíamos dizer que há a psicodinâmica do trabalho, que Christophe Dejours continua a desenvolver juntamente com outros pesquisadores, também a ergonomia e a clínica da atividade. A psicologia do trabalho é muito vasta na França. Há a psicologia do trabalho cognitiva, a psicologia ergonômica, que segue a tradição de Faverge, de Leplat, e também há a psicologia industrial, a psicologia do trabalho e das organizações, que ainda é importante quantitativamente, mas quanto à característica teórica, não é muito forte. De certa maneira, na França, nós, da clínica do trabalho, somos "pequenos", mas importantes, eu penso, do ponto de vista de referência na disciplina.

Leny - E porque o emprego da palavra "clínica"? Clínica do trabalho.

Clot - Clínica do trabalho porque é uma idéia de que é uma disciplina clínica, no sentido médico: tem como objeto uma doença nas situações reais de trabalho. Baseia-se na idéia de que a psicologia do trabalho vai partir do campo (da realidade de trabalho) e voltar ao campo. É uma idéia de que não há psicologia do trabalho sem transformação da situação de trabalho.

Henrique - Qual a relação entre a clínica do trabalho e a ergonomia?

Clot - Nós buscamos transformar o trabalho. Isso é justamente o que nós partilhamos com a ergonomia. A ergonomia de Wisner apresenta a concepção de que se deve adaptar o trabalho ao homem e não o homem ao trabalho, e toda a tradição da psicologia industrial visa

5 Alan Wisner é autor do livro Por dentro do trabalho - ergonomia: método Ė técnica, publicado em São Paulo pelas editoras FTD e Oboré em 1987. 
justamente adaptar o homem ao trabalho, quer dizer, conformá-lo. Ela analisa a disfunção, mas a disfunção dos homens e não a disfunção da situação, da organização. É verdade que a tradição ergonômica tem como objetivo a ação, a transformação. É verdade, que o objetivo é compreender para transformar. Nesse sentido, eu penso que a ergonomia também é clínica, desse ponto de vista, quer dizer, é um dispositivo de transformação da situação e de restauração da saúde. É por isso que é clínica, por buscar transformar a situação, e é clínica também em função do modelo teórico. Evidentemente, quando dizemos "clínico" em psicologia pensamos imediatamente na psicanálise, é por isso que podemos dizer que a psicodinâmica do trabalho, na tradição psicanalítica, é também uma clínica do trabalho. É verdade, eu decidi manter a idéia de "clínica" ao lado, colada, digamos assim, à de "atividade", "clínica da atividade", porque eu insisto no fato de que não podemos tratar da atividade sem tratar da subjetividade. De certa forma, a diferença entre a ergonomia e a "clínica da atividade" reside no fato de que atividade e subjetividade são inseparáveis e é essa dupla - atividade e subjetividade - que me interessou na situação de trabalho. Por isso que uso o termo "clínico": clínico do ponto de vista de meu engajamento, do lado da experiência vivida, do sentido do trabalho e do não sentido do trabalho; "clínico" do ponto de vista da restauração da capacidade diminuída. A clínica médica visa restaurar a saúde, a "clínica" é a ação para restituir o poder do sujeito sobre a situação. Essa idéia eu tomo porque eu tenho em conta uma tradição em psicopatologia do trabalho dada pelos trabalhos de Le Guillant que tem como característica o reencontro da clínica sem ter como referência essencialmente a psicanálise; por isso eu me interessei por Le Guillant. Eu parti dele também. Podemos dizer que na França há uma escola da "clínica do trabalho" e, muito no CNAM, da psicodinâmica do trabalho e da clínica da atividade. Para voltar à sua questão, é verdade que na clínica do trabalho a questão do coletivo é o problema central. Não é o coletivo como grupo, mas o coletivo como recurso para o desenvolvimento da subjetividade individual; é o coletivo no indivíduo que nos interessa. Por isso Vigotski é tão importante. Vigotski apresenta a idéia de que o social não é simplesmente uma coleção de indivíduos, não é simplesmente o encontro de pessoas; o social está em nós, no corpo, no pensamento; de certa maneira, é um recurso muito importante para o desenvolvimento da subjetividade. Nesse sentido, o coletivo não é uma coleção, é o contrário da coleção. O coletivo, nesse sentido, é entendido como recurso para o desenvolvimento individual. É isso o que interessa à clínica da atividade. Há uma dimensão coletiva e subjetiva.

Dulce - Você conhece Vincent de Gaulejac?

Clot - Sim.

Dulce - Ele trabalha com a sociologia clínica. Há alguma relação entre a sua teoria e a dele?

Clot - Nos conhecemos, claro! Mas não há relação de trabalho regular com ele. Nos encontramos em seminários e nós discutimos. A concepção que tenho da "clínica" é buscar a transformação, por isso minha afinidade com Oddone. A clínica não é apenas para conhecer, mas é um dispositivo de ação e do conhecimento para a ação, para a transformação, por isso minha ligação com Oddone. Há uma tradição na sociologia em que a idéia de clínica vinculase a descrever as situações e meu interesse não reside apenas em descrever as situações. Há muitas abordagens na sociologia clínica, podemos discutir isso por horas. Há também a tradição da psicossociologia, com Eugène Enriquez e com outros que têm proximidade com o que fazemos. Para mim o interesse reside não no conhecimento em si, na descrição, mas na transformação. Há contribuições importantes de Vincent de Gaulejac que explicam os mecanismos de funcionamento organizacional, no sentido da sociologia clássica. Há os trabalhos de Eugène Enriquez, também muito importantes. Todos oferecem contribuições importantes, mas, para mim, o objetivo do conhecimento científico é como um mecanismo para o desenvolvimento da ação, agimos para transformar a situação. Mais especificamente, nós estudamos como a ação se desenvolve, esse é um verdadeiro problema científico, que nós desenvolvemos com a abordagem vigotskiana sobre o estudo do desenvolvimento; a ação é 
objeto científico e é a ação que transforma a situação, com os operadores, os trabalhadores. A pesquisa é um meio para transformar, não é a pesquisa-ação. Nessa situação nós temos os instrumentos para desenvolver a capacidade de agir dos operadores.

Henrique - Quero aproveitar um pouco essa comparação entre sociologia e psicologia. A sociologia diz que nós nos dirigimos, hoje, principalmente, para a individualização do trabalho; uma relação que tenta destruir a cooperação que os trabalhadores tinham, mesmo nas fábricas fordistas, mesmo na contra-corrente, há uma espécie de diagnóstico do mal-estar produzido por essa individualização, pois as soluções individuais são usualmente frágeis.

Clot - Eu não creio que o mundo do trabalho atual esteja afetado por uma única tendência em direção à individualização. Eu trabalho com muitas empresas. Há uma verdadeira contradição na gestão profissional, na indústria e nos serviços, sobretudo na área de serviços. Certamente, a gestão tende a individualizar as questões e os sociólogos têm insistido muito nisso, mas o real do trabalho impõe, cada vez mais, um trabalho coletivo; para fazerem face ao real, os trabalhadores têm que fazê-lo juntos. No mundo do trabalho atual há uma gestão individualizante, mas há uma necessidade muito, muito forte do coletivo. E o coletivo não é simplesmente um valor que deveria ser defendido contra a corrente de uma sociedade que vai contra o coletivo. Eu creio que a questão do coletivo merece ser aprofundada como uma tendência do lado do real do trabalho. Isso quer dizer que o coletivo não é qualquer coisa que deve ser defendido, mas algo que deve ser reencontrado; ele é algo que é solicitado e, ao mesmo tempo, interditado. Eu creio que no mundo do trabalho atual, na indústria e nos serviços, sobretudo na área de serviços, o coletivo é a fonte do real. O coletivo é solicitado e, ao mesmo tempo, interditado e eu penso que é a causa profunda do sofrimento no nível profissional. A necessidade do coletivo combatida pela organização que será vivida como dificuldade no nível individual. Eu creio que o que nós fazemos na psicologia do trabalho, na clínica do trabalho não é defender um valor antigo do coletivo; eu penso que nós estamos bem habilitados para saber que a organização do trabalho oficial tenta rechaçar o coletivo, mas esse coletivo é qualquer coisa que é demandada pelo real do trabalho. Assim, eu sou bastante crítico sobre certas descrições sociológicas do trabalho atual, que retêm uma única tendência.

Henrique - Jean-Pierre Durand, em suas pesquisas, tem denominado a ausência de resistência dos trabalhadores como uma servidão voluntária. $O$ que você pensa desse diagnóstico sombrio.

Clot - Há muitas demandas para restaurar a profissão como uma história coletiva. $\mathrm{Na}$ construção civil, nas empresas privadas (não nas empresas públicas, mas nas grandes empresas privadas), e dentre elas, as indústrias, é que se coloca atualmente a questão de saber se a perenidade de sua eficácia não estaria ligada à restauração das histórias coletivas de transmissão (do conhecimento) profissional. Eu creio que a descrição sociológica deforma a contradição no mundo do trabalho. De um lado, há uma estratégia gerencial da individualização que impulsiona o individualismo na sociedade - é verdade, não há razão para discutir isso -, mas, na verdade, a organização do trabalho recusa o coletivo e num outro lugar o solicita.

Leny - Nesse aspecto que você refere, de no setor da construção civil e nas grandes empresas para recuperar essa história da profissão, será que não estaria ligado ao que hoje as empresas dizem que é necessário que os trabalhadores tenham comprometimento? Será que essas coisas estão ligadas? Será que há um controle simbólico?

Maria Chalfin Coutinho - Aproveitando, deixe-me colocar uma questão, que eu li num texto que você escreveu, que apontava para o fato de os modos de gestão prescreverem modos de subjetividade do trabalhador, do tipo just in time. 
Clot - Sim, certamente que há demanda de prescrição da subjetividade, ou seja, a mobilização subjetiva no trabalho demanda uma fabricação de "coleção". O indivíduo voltado para a sua tarefa, infelizmente. Certamente essa demanda existe, o comando clássico, mas esse comando, na verdade, contraditoriamente, é trabalhado pelo coletivo, e não pela coleção. O coletivo é a profissão como história comum, do gesto partilhado a ser transmitido por herança como história coletiva do pensar sobre o trabalho. Para responder sua pergunta: é uma batalha complicada certamente. Ao comando que divisa a mobilização subjetiva para fabricar uma coleção de indivíduos, nós trabalhamos com esse comando, contra esse comando, além desse comando, com a idéia de que a implicação subjetiva no trabalho supõe ser também des-identificado. A implicação subjetiva no trabalho supõe, finalmente, suspender a atividade para pensar a atividade em conjunto. O que nós fazemos vai no sentido oposto: se a demanda da empresa é a construção da coleção, nós buscamos a construção do coletivo. Eu não me interesso em profetizar o mundo futuro, interesso-me que na situação real, no comando real da empresa, nós possamos trabalhar sobre as histórias coletivas das profissões que se transmitem, e é possível que essa seja uma condição pela qual o próprio mundo do trabalho se interesse. Há uma dificuldade do sindicalismo em interessar-se verdadeiramente pelo trabalho, pela qualidade do trabalho, no sentido do prazer de trabalhar junto. Eu passei a minha vida descrevendo as estratégias gerenciais e conheço dezenas delas. A questão é como desenvolver estratégias de ação, que é a resposta de Oddone, por meio do real do trabalho, desenvolver estratégias de ação alternativas, isso é o que me interessa. Há uma estratégia de prescrição da subjetividade, de conformar-se aos ideais das empresas. Nós utilizamos o dispositivo da ação para desenvolver o coletivo. A nossa ação tem limites, é pequena, mas é uma maneira de conservar viva a tradição aberta por Oddone, numa conjuntura histórica que não é favorável para o desenvolvimento do mundo do trabalho.

Leny - Ontem você falou no nosso GT $^{6}$ que você tem uma preocupação de desenvolver pesquisas que estejam fortemente vinculadas à possibilidade de transformação - conhecer para transformar - e que é importante trabalhar a partir de uma demanda. E você falou também que muitas vezes essa demanda não está posta, que é necessário que se desenvolva um caminho anterior para que a demanda exista. Eu queria que você falasse um pouco sobre esse processo: de um momento em que não existe uma demanda para aquele no qual ela passa a existir.

Clot - Quando eu trabalhei com os grupos homogêneos na década de 1970, havia o mesmo problema na linha de montagem da Fiat, em Turim. Não havia uma demanda espontânea, ela deveria ser construída. Oddone lutava contra o que ele chamava de monetarização do risco, em que os agravos à saúde são utilizados pelos trabalhadores como meio de reivindicação salarial, vender a saúde como forma de compensação ${ }^{7}$. A estratégia de Oddone era a de transformar essa demanda de monetarização do risco em uma apropriação coletiva das condições de trabalho. A demanda espontânea dos trabalhadores é freqüentemente (frente à relação de força) a de tentar tirar o melhor partido da situação de fraqueza em termos salariais, então, nós sempre temos o mesmo processo. No diálogo com os trabalhadores nós podemos trabalhar essa demanda para restaurar a capacidade de agir na situação. É muito importante saber que o trabalhador não faz parte do trabalho no sentido de ser um insumo, de um recurso a ser "gasto". E, como fala Oddone, quando ocorre de os trabalhadores buscarem a monetarização do risco, de sua saúde, a fim de obter ganhos monetários, isso é, de certa maneira, prioritariamente, vender a saúde. É como se a saúde fizesse parte do trabalho nesse sentido. Não se trata então de compensar esses agravos, sob o ponto de vista da reivindicação salarial, de modo que não signifique a degradação do trabalho, mas sim deslocar

6 Aqui Leny Sato refere-se à participação de Yves Clot em uma sessão do Grupo de Trabalho "Trabalho e processos organizativos na contemporaneidade" no XI Simpósio da Anpepp de 2006.

7 No Brasil, por exemplo, temos, figurando na legislação trabalhista, a figura dos "adicionais" salariais em função de o trabalho dar-se em condições consideradas insalubres e perigosas, como os adicionais de insalubridade e de periculosidade.

\section{4}


a questão sobre o objeto real do trabalho, que é trazer a controvérsia sobre a qualidade do trabalho. Penso que é muito importante tomar uma posição não neutra (que certamente não existe), mas uma posição forte que permita tomar uma direção que trabalhe precisamente essa história coletiva que se transmite. Eu penso que o nosso trabalho tem uma ancoragem muito, muito forte sobre a qualidade do trabalho, que é também da beleza do gesto bem feito, da coisa bem pensada, da coisa alcançada. Essa é a melhor garantia da saúde. E isso não é negociável.

Maria - Como no caso da telefonista dos serviços em callcenters que fala todo dia a mesma coisa. É um trabalho que não é belo.

Clot - É um trabalho em que se fala sem pensar. Há também uma interdição posta sobre a possibilidade de pensar conjuntamente sobre o gesto, o que leva à utilização do telefone para falar sem pensar: há um script lingüístico e comportamental dentro do qual eu me encontro numa posição de falar sem pensar, mas ainda assim há o pensamento a ser dito, há o sentimento a ser expresso. Há muita atividade impedida e é por isso que as pessoas não podem trabalhar muito tempo nesses lugares. Essa é justamente a situação de organização do trabalho que luta contra a organização coletiva. E se as pessoas não podem pensar em conjunto, o que elas fazem? Há, por exemplo, o recurso da rotatividade. Há o caso de pessoas que trabalham lá (como telefonistas) e que não conseguem descansar. $O$ coletivo é sacrificado.

Leny - Para complementar o que você já nos apresentou, queria que você falasse mais sobre o que consiste a clínica da atividade.

\section{Henrique - E o que é atividade?}

Clot - A atividade, na tradição vigotskiana, não é "operação”. Eu diria que, para mim, há uma equivalência entre "atividade" e "saúde". Eu adoto uma definição filosófica de saúde trazida por Georges Canguilhem ${ }^{8}$. Se nós definimos saúde segundo a leitura de Canguilhem, no mundo do trabalho atual, penso que a saúde está gravemente em perigo. As pessoas usam seus recursos pessoais para preservar a saúde. Para mim, a atividade é contribuir para uma história que não é minha e criar entre as coisas uma relação que não foi construída. A atividade não é operação (gesto visível, detalhe etc.), mas sim o que é feito e o que ainda não foi feito. O sonho é parte da atividade. Inclui o que eu fiz e o que eu não fiz. O que eu não fiz, paradoxalmente, faz parte da atividade. É uma concepção de atividade que toma a enunciação, de Bakhtin, que define o enunciado como um tipo de conflito possível. A atividade é uma colisão de possíveis. Então, com uma concepção de atividade que é equivalente à de saúde, a clínica da atividade é um dispositivo clínico que nós utilizamos para pesquisar o que não foi realizado para restaurar o possível da atividade, para ver e mostrar o

\footnotetext{
8 Esse trecho teve sua compreensão prejudicada por problemas da gravação. Trata-se de uma passagem na qual o entrevistado recorre à reflexão de Georges Canguilhem para relacionar "saúde” e "atividade". Em função disso, reproduzimos abaixo trechos de um artigo de sua autoria no qual essa reflexão pode ser encontrada: "Canguilhem escreve que é necessário reconhecer no organismo 'a existência de um sistema de réplicas de autodefesa' que preserva sua saúde e autoriza a 'reversão da proteção em ataque'. Em outras palavras, a doença é a expressão da vida (...). 'A patologia é uma exploração de diferentes ordens fisiológicas possíveis.' (...) Paradoxalmente, portanto, a saúde do sujeito se prova passando pelo desvio da patologia. Como aponta Canguilhem: 'é a indiferença de um ser vivo às suas condições de vida, à qualidade de suas trocas com o meio que é profundamente anormal'. Em outras palavras, 'estar com boa saúde é poder cair doente e se recuperar, é um luxo biológico'. Pois 'o estado mórbido é sempre uma certo modo de viver' (...). A reflexão de Canguilhem nos alerta para obstáculos com os quais nossa clínica das atividades de trabalho se depara freqüentemente: 'pelo excesso de suas reações de defesa, o organismo pode se comportar de modo a cooperar com seu agressor'. Com efeito, para manter uma espécie de constância vital, o doente pode se instalar em um meio empobrecido. Nesse caso, a doença é 'a instauração de novas normas de vida pela redução do nível de atividade na relação com um meio novo, mas reduzido. Para Canguilhem, o doente é doente porque 'só pode admitir uma única norma', doente por não ser mais normativo. Em outros termos, se a defesa é bem 'uma nova dimensão da vida', ela é igualmente uma diminuição da vida. Pois, se viver é preferir se excluir - o que complica seriamente a doença reduzindo as margens de manobra do doente - a patologia é bem 'um sentimento de vida contrariada"'. "Assim, a preservação da normalidade, um estado de equilíbrio, não permite alcançar a saúde enquanto tal, pois 'a normalidade é a admissão de uma norma, a adaptação a um meio e às suas exigências, enquanto sentir-se com boa saúde', insiste Canguilhem, é 'sentir-se mais do que normal', 'capaz de seguir novas normas de vida', instigador de normas, sujeito vivo de uma normatividade”. Yves Clot (2001), Psychopathologie du travail et clinique de l'activité, publicado na Revue Éducation Permanent, 146 (1), 35-46.
} 
que não é possível; então, a clínica da atividade é a clínica da saúde nesse sentido. Eu penso que a clínica da atividade é um aporte bastante compatível com o vigotskiano, no que se refere à criação e ao desenvolvimento, e é incompatível com uma concepção da atividade como operação. Penso que é muito importante conceber a atividade dessa forma pois ela põe a questão da subjetividade no interior da atividade porque quando eu falo de atividade impedida, de atividade recriada, eu falo da mobilização subjetiva.

Leny - As perspectivas de Bakhtin e de Vigostki oferecem subsídios para a abordagem que você desenvolve. Eu queria que você falasse como se deu o desenvolvimento do método que você se utiliza para analisar a atividade. Você se referiu ontem", na apresentação, ao "real da atividade" e à "atividade realizada" e você desenvolveu um método, que compreende a observação, a auto-confrontação e a auto-confrontação cruzada.

Clot - Nesse método há uma concepção vigotskiana. O pensamento se desenvolve na discussão, na confrontação e, portanto, a controvérsia é a fonte do pensamento. Então, Vigotski diz que o pensamento nasce duas vezes. A primeira vez quando se discute coletivamente e renasce, em seguida, na atividade individual. É o duplo nascimento do pensamento, segundo Vigotski. A meu ver, esse é o seu ensinamento mais importante. Se bem que os métodos da auto-confrontação cruzada, do diálogo no coletivo, da controvérsia no coletivo são muito característicos, a meu ver, do método indireto que ele desenvolveu em psicologia, que consiste em tentar se apropriar do objeto pela mediação de outro, por meio do conflito entre as pessoas. Esse método não é apenas empírico, mas há todo um aparato conceitual. Assim, nas situações criadas no método, os trabalhadores são solicitados a pensar. Pede-se a trabalhadores da mesma profissão que discutam seu trabalho. A descoberta prática é de que o diálogo profissional é uma fonte do pensamento individual, assim, o coletivo é uma fonte do pensamento individual. Coletivo entendido como confrontação e intercâmbio. O coletivo, então, é compreendido como controvérsia. Eu diria que não há uma aplicação do método de Vigotski na situação de trabalho, mas que foi uma redescoberta dele para pensar o problema prático no campo ${ }^{10}$.

Leny - Baseando-me nas minhas pesquisas - em que uso a abordagem etnográfica, a convivência prolongada com as pessoas no trabalho -, a mim me parece que o que ocorre é uma confrontação cotidiana entre diversos racionais, que conduzem a refletir sobre diversas escolhas organizacionais, mesmo em trabalhos taylorizados, em linhas de montagem. E disso decorrem micro-mudanças, micro-negociações sem a concorrência de um pesquisador. Você partilha dessa constatação?

Clot - Eu penso que, no dia-a-dia do trabalho normal, o que nós fazemos (os métodos da auto-confrontação e da auto-confrontação cruzada) se passa sem parar. A clínica da atividade visa a restaurar o ambiente do trabalho normal. A clínica da atividade não é outra coisa senão a reabilitação da função ordinária do trabalho. Nós repetimos e sistematizamos a vida ordinária. E para mim, isso é muito, muito importante. Trata-se de redescobrir ou de reencontrar o recurso interno do meio profissional considerado. Simplesmente o que é importante. E para mim essa é a diferença dos paradigmas de pesquisa: é que o problema não é desenvolver a interpretação do pesquisador, os diferentes modelos de interpretação do real, do lado do pesquisador, para mim, e continuo com Oddone, o importante é desenvolver a interpretação dos trabalhadores, não a do pesquisador. É um dispositivo com o qual os trabalhadores reinterpretam a sua interpretação e desenvolvem a sua interpretação sobre o trabalho que fazem. Isso é psicologia: o desenvolvimento do pensamento e da atividade dos trabalhadores por eles mesmos. Isso é muito interessante. A observação reencontra a primeira observação. A primeira observação é objeto de observação e de reflexão. Eu penso que o

9 Leny Sato referia-se, aqui à palestra proferida por Yves Clot durante o XI Simpósio da Anpepp, sobre metodologia de análise do trabalho em 2006.

10 Yves Clot inspirou-se no método de Vigotski para criar o método adotado na análise do trabalho.

\section{6}


importante é a história da observação, é a história da observação dentro da observação. A clínica da atividade é isso: é como recurso para que os protagonistas da observação e da interpretação se transformem. Os operadores, os trabalhadores, transformam-se em sujeitos da interpretação e da observação e não se reduzem a objeto da interpretação e da observação dos pesquisadores. Nesse sentido, há uma ruptura epistemológica, a que Oddone fez na psicologia do trabalho. E justamente o mais interessante é que várias pessoas, vários trabalhadores dizem coisas diferentes. É a fonte de interpretação do real.

Leny - Bem, professor Clot, creio que essa entrevista ajuda-nos a compreender a sua proposição teórica. Muito obrigada! 


\section{Cadernos de Psicologia Social do Trabalho}

\section{Pedido de assinatura e de exemplares avulsos}

Para fazer uma assinatura ou solicitar qualquer exemplar avulso, envie-nos a ficha abaixo preenchida e cheque nominal ao Instituto de Psicologia - USP. Por gentileza, escreva ou telefone para saber os valores atuais de cada exemplar ou da assinatura.

Centro de Psicologia Aplicada ao Trabalho

Av. Prof. Mello Moraes, 1721

Bloco D, sala 163

Cidade Universitária, São Paulo/ SP

05508-030

Endereço eletrônico: cpat@usp.br

\begin{tabular}{|l|l|c|c|}
\hline Quantidade & \multicolumn{1}{|c|}{ Pedido } & \multicolumn{1}{|c|}{ Valor $^{*}$} & \multicolumn{1}{|c|}{ Total } \\
\hline & volume 1 & esgotado & esgotado \\
\hline & volume 2 & & \\
\hline & volume 3/4 & & \\
\hline & volume 5 & & \\
\hline & volume 6 & & \\
\hline & $\begin{array}{l}\text { volume 7 } \\
\text { volume 8 }\end{array}$ & & \\
\hline & volume 9, número 1 & Total: R\$ \\
\hline & assinatura por dois anos (quatro exemplares) & & \\
\hline & & & \\
\hline
\end{tabular}

" Por favor, consultem-nos a respeito dos valores antes de fazer seus pedidos.

\begin{tabular}{|c|c|c|}
\hline Nome: & & \\
\hline Endereço: & & \\
\hline & & CEP: \\
\hline Cidade: & & Estado: \\
\hline Telefone: ( ) & E-mail: & \\
\hline Data: / / & Assinatura: & \\
\hline
\end{tabular}

